\title{
Biotecnologia (não apenas "Bio" mas também "Tecnologia")*
}

Hoje em dia a biotecnologia é considerada uma das tendências mais dinâmicas no desenvolvimento de forças produtivas.

É necessário fazer um balanço periódico das suas possibilidades, fronteiras e limitaçðes pois trata-se de uma ciência em evolução. Torna-se também indispensável um enquadramento teórico das várias tecnologias. Este artigo descreve em linhas gerais o que é a biotecnologia e analisa os seus métodos e teorias, num quadro geral.

\section{A Biotecnologia como tecnologia chave}

O interesse da biotecnologia tem vindo a crescer rapidamente nos últimos anos e presentemente é considerada uma tecnologia fundamental. Isto deve-se sobretudo ao desenvolvimento das ciências biológicas. A descoberta do código genético e a manipulação de organismos vivos através de intervenção intencional, química e bioquímica, ao nível da estrutura genética, pode ser comparada em importância à descoberta da electricidade e do magnetismo ( $\left.{ }^{1}\right)$. Os resultados obtidos na bioquímica, microbiologia, imunologia e neurobiologia levaram ao desenvolvimento de técnicas de produção que terão forte impacto na indústria, agricultura, ecologia, serviços de saúde e outras esferas da vida humana, além dos efeitos mais remotos na estrutura e metodologia de produção actuais.

A crise energética e de matérias-primas dos anos 70 alertou-nos a todos para a existência de reservas limitadas e distribuição desiquilibrada dos recursos naturais terrestres. A biotecnologia, por via dos seus eficientes mecanismos biologicos de síntese tem vindo a ser cada vez mais utilizada para se tirar partido das matérias-primas renováveis. Está portanto a contribuir para o melhoramento da gestão económica dos recursos mundiais. Contudo, o desenvolvimento de novas técnicas de produção só terá sucesso se os métodos introduzidos forem mais económicos do que os vulgarmente empregues.

A pergunta chave é pois: Será a biotecnologia capaz de encontrar métodos de produção mais lucrativos do que os mais avançados usados actualmente? Os progressos mais recentes na indústria química visam:

- um aumento de concentração da produção (usando matérias base compactas e processos de alta velocidade);

- uma densidade de fluxo de energia superior (através de campos de excitção fortes para as reacçōes);

- maiores áreas de estabilidade dos sistemas usados (através de meios auxiliares mais duráveis).

Estas tendências têm um sentido oposto ao dos processos biológicos, que são caracterizados por:

- um grau de diluição superior (devido a excitações distributivas como, por exemplo, em sistemas fototró-

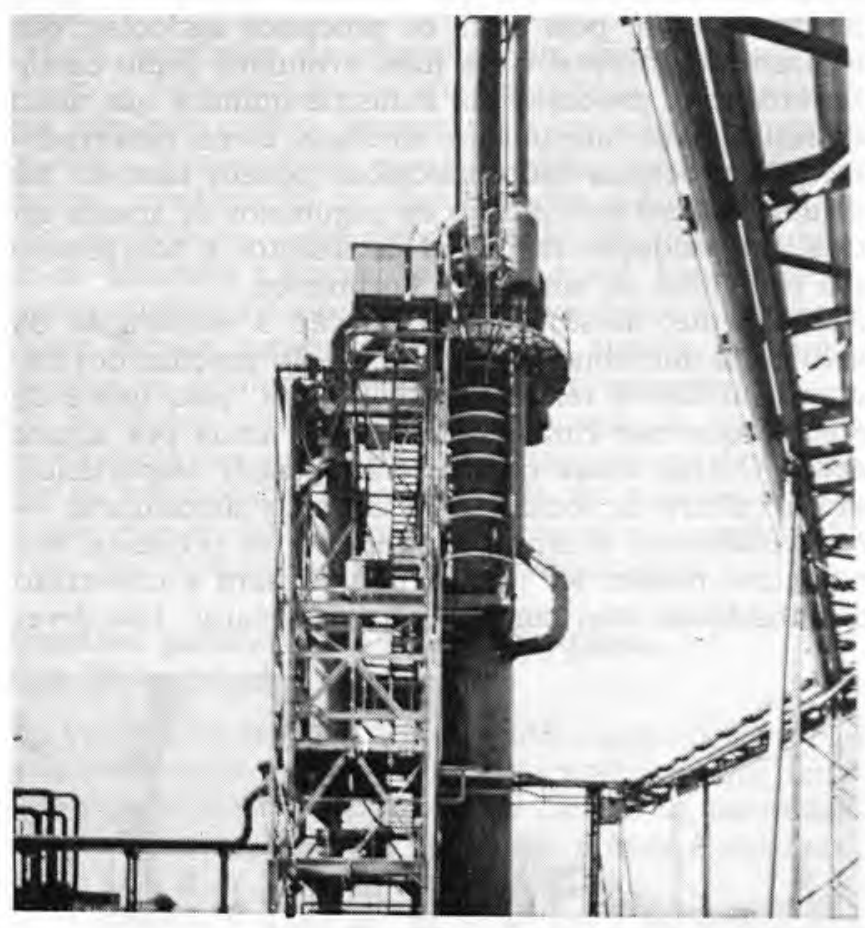

Fig. 1

Fermentador de alta eficiência para fermentaçôes aeróbias de dimensão média (Agro-Chemisches Kombinat Piesteritz/RDA)

picos) ou, pelo menos, certo grau de diluição que não pode ser evitado completamente (devido à necessidade de se ter uma estrutura mais solta para garantir a reacção);

- uma velocidade global de reacção mais baixa (devido às baixas excitaçð̃es das reacçð̋es e à complexidade dos mecanismos);

- limites de estabilidade mais próximos (devido a necessidades ambientais, como a temperatura, concentração e presença de água).

Por outro lado os processos biológicos possuem várias vantagens em relação aos processos químicos, nomeadamente:

- selectividade completa (uma substância reage na presença de muitas outras) e especificidade (muitas substâncias originam o mesmo produto, ou uma substância produz um produto);

- propriedades de auto-reprodução e auto-reparação;

* Traduzido de Chemistry Internacional Vol. 7, Outubro de 1985, por Maria José Miranda de Castro, IST.

a Institut für Technische Chemie der Akademie der Wissenschaften Dder DR, Leipzig, República Democrática da Alemanha. 
- aproveitamento de matérias-primas heterogéneas e diluídas, que frequentemente não podem ser usadas com qualquer outro método.

\section{Objecto da biotecnologia}

A biotecnologia envolve a investigação, desenvolvimento e descrição de processos industriais em que os princípios de acção biologicos são decisivos. Estes incluem os processos biotecnológicos na indústria alimentar e indústrias relacionadas, nas indústrias química e farmacêutica e no abastecimento de águas, agricultura e mineração. A tarefa principal associada a estes processos é a conversão de substâncias, tirando partido das propriedades catalíticas dos sistemas biológicos. Estes processos estão pois entre os processos agrícolas, que utilizam organismos vivos mais evoluidos como catalizadores, e os processos da indústria química que usam exclusivamente substâncias abióticas como catalizadores. Os processos biotecnologicos podem também ter algum impacto em culturas de cogumelos de grande escala, na produção industrial de insectos e nos processos catalíticos de simulação enzimática.

Actualmente, dá-se especial atenção à exploração da actividade microbiana. A manipulação genética dos microorganismos é relativamente simples, pelo que é de esperar que este ênfase se mantenha ainda por alguns anos. Outras áreas que deverão ganhar importância são a cultura de tecidos e de sistemas subcelulares particularmente enzimas. No entanto, os processos tecnológicos podem ser usados não só para a conversão de substâncias mas também para as separar. Isto deve-

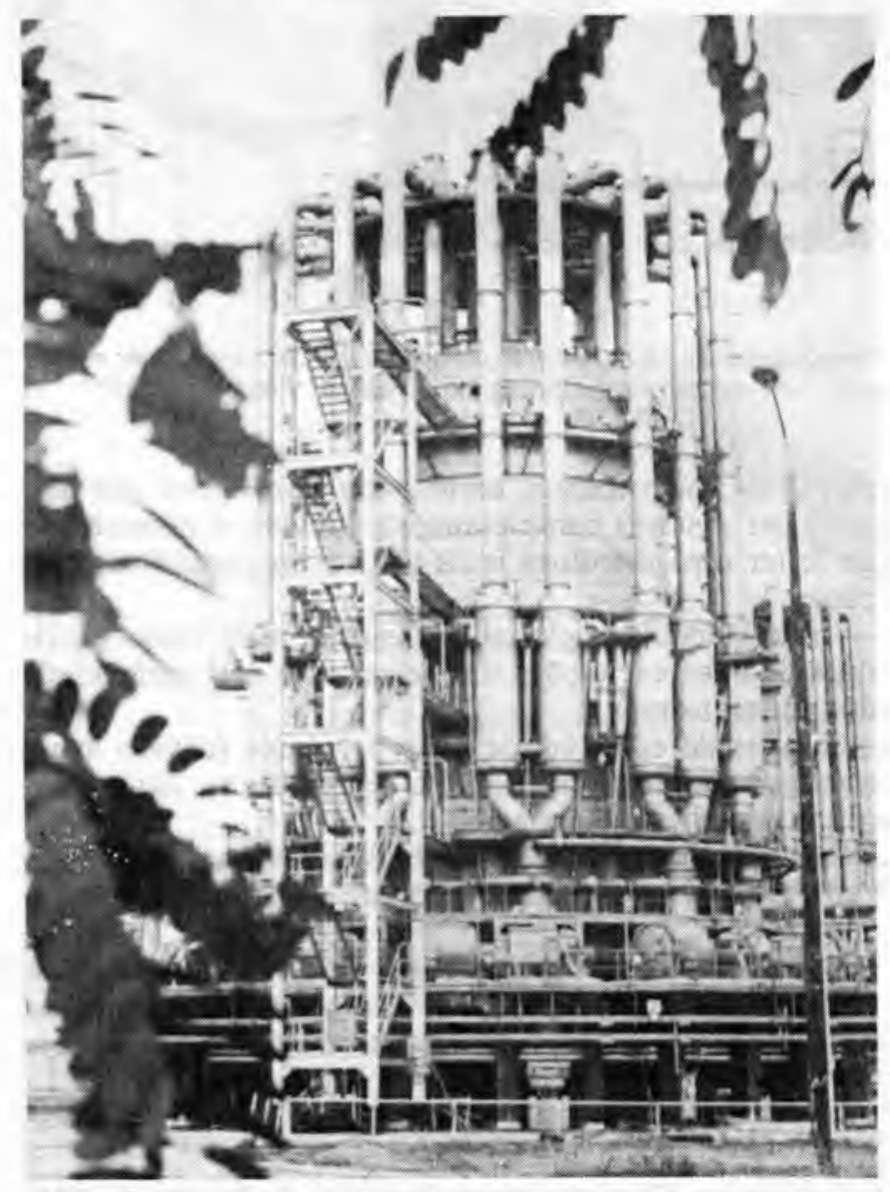

Fig. 2.

Fermentador de alta eficiência para fermentação aeróbias em larga escala (Petral Chemisches Kombinat Schwedt/RDA) -se à capacidade que certas moléculas biológicas têm para o reconhecimento de outras e para se ligarem entre si.

A esfera de acção da biotecnologia será sem dúvida alargada num futuro próximo, o que dependerá do avanço das ciências naturais, como por exemplo a bioquímica de moléculas com importância industrial. O desenvolvimento técnico será outro factor decisivo, como por exemplo o desenvolvimento de reactores específicos e dispositivos de controlo para os processos biologicos.

\section{Método da Biotecnologia}

Os métodos da biotecnologia têm de ser baseados em princípios biológicos e além disso obedecer aos métodos da tecnologia.

A maior dificuldade na compreensão dos métodos da biotecnologia deve-se à inexistência de uma tecnologia geral. A tecnologia, como ciência, manifesta-se presentemente apenas em formas específicas, como por exemplo, a tecnologia química, a tecnologia nuclear e a biotecnologia. Isto tem impedido a sistematização e o uso dos métodos gerais válidos para qualquer tecnologia específica. Em relação a este assunto existem vários pontos que importa referir:

1. A obtenção de conhecimento nas ciências naturais e a sua aplicação na produção está a acontecer com uma velocidade cada vez maior.

2. Os métodos científicos estão a ser progressivamente mais usados na produção. Como resultado, a velocidade de crescimento das ciências técnicas está a aumentar.

3. A fusão da ciência com a produção está a tornar-se um veículo decisivo para o desenvolvimento económico.

Contudo, o desenvolvimento de uma tecnologia geral não pode ser separado das suas manifestaçð̄es próprias. A investigação científica traz novos princípios de trabalho cuja realização técnica requer o desenvolvimento de formas específicas de tecnologia. Mais uma vez, isto poderia ser facilitado e acelerado pelo desenvolvimento e existência de uma tecnologia geral, e uma tecnologia geral - à custa da sua variedade de manifestaçð̄es - será necessariamente alargada e enriquecida.

Presentemente, a inovação, a optimização, o projecto da fábrica e o equilibrio e adaptação a sistemas de economia superordenados são considerados os métodos mais importantes de uma tecnologia geral. Derivam dos processos gerais de desenvolvimento e produção, que por sua vez são gerados pelas necessidades sociais e resultados científicos. A biotecnologia activa alguns resultados das descobertas biologicas e desenvolve as medidas técnicas correspondentes.

As manifestaçōes concretas revelam muito claramente a natureza interdisciplinar da tecnologia como ciência. Esta natureza diminuirá com a transição para uma tecnologia geral, que pretende ser a ciência dos processos da produção em geral e não de todos os processos individuais. Como ciência, combina o conhecimento biologico e a metodologia tecnologica geral.

\section{Teoria da Biotecnologia}

Qualquer campo do conhecimento com pretensठes a ser ciência deverá ter a sua estrutura teórica própria. É discutível que tal seja verdade em relação à tecnologia em geral e à biotecnologia em particular. Seria um erro 


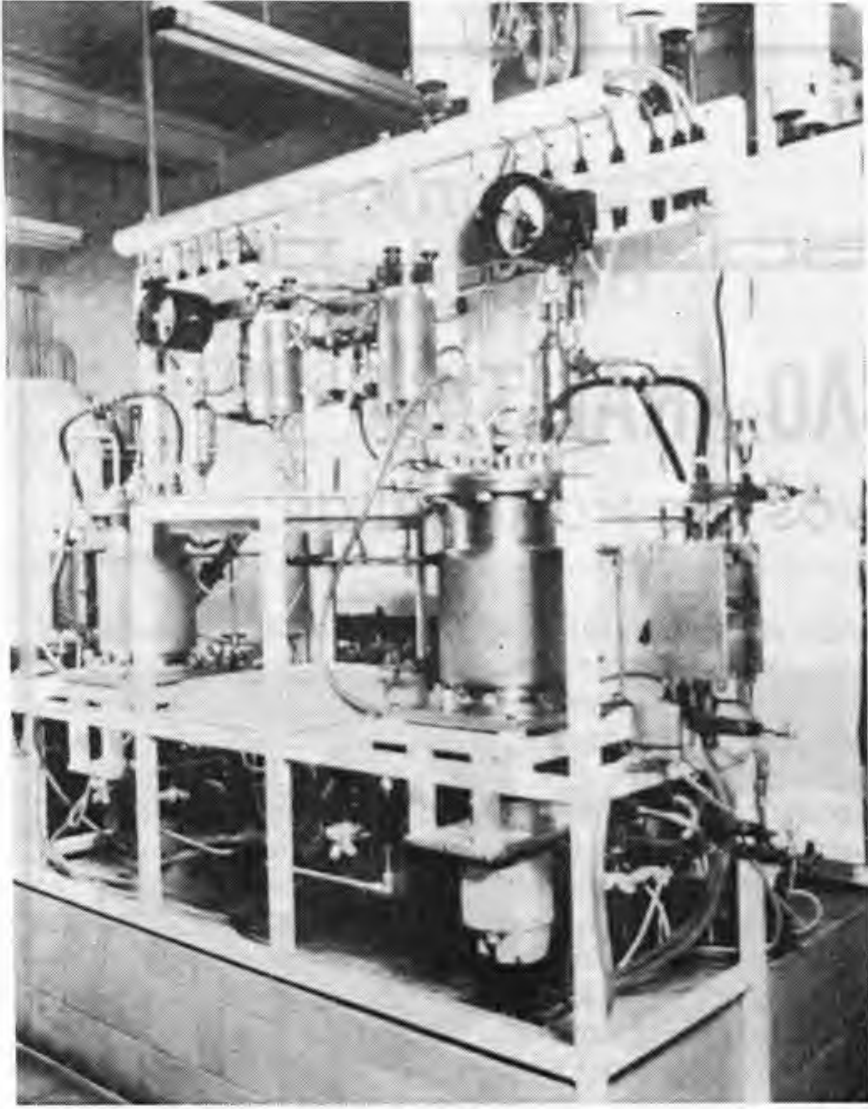

Fig. 3

Fermentadores de pressão para estudos laboratoriais de fermentaçбes aeróbias e anaeróbias (localizado no Instituto de Biotecnologia, Leipzig)

básico admitir que as teorias especificas da ciência biológica são também válidas para a biotecnologia. Quando muito, o acesso a este problema será possível através da definição de uma tecnologia geral. A tecnologia assinala caminhos para os processos de produção. Assim, cada caminho deveria ser um elemento da teoria da tecnologia: a estas directrizes particulares chamamos conceitos $\left(^{3}\right)$. Os seus componentes são uma ou mais descobertas científicas que actuam economicamente através da aplicação técnica. O chamado conceito de máximo é exemplo de um desses conceitos.

"Para cada processo de produção particular existe um estado que mostra os seus parâmetros máximos possíveis, cientificamente definidos - o estado máximo desse processo. A distância entre o estado máximo e os estados industriais já realizados é considerada o campo (ou espaço) disponível para as pesquisas tecnológicas com vista ao melhoramento do processo. Aproximar os parâmetros do processo dos valores máximos equivalentes pode resultar num campo (ou espaço) em que qualquer número de estados são mais lucrativos do que aqueles realizados industrialmente. A proporção entre a aproximação ao estado máximo do processo e o estado mais favorável economicamente é uma medida da qualidade da investigação tecnológica".

Esta afirmação pode dar lugar à objecção de que a existência de um estado máximo de processo é discutível, do ponto de vista da teoria do conhecimento. Nesta altura temos de dizer que um estado máximo de processo é definido pelo nível de conhecimento científico. Por exemplo, um processo de crescimento microbiano atinge um estado máximo, que é definido como o resultado da taxa específica de crescimento máximo e concentração celular possível máxima. Se uma taxa espécífica de crescimento mais elevada fôr imposta, por exemplo, através de manipulação genética, então atingir-se-á um novo estado máximo do processo.

O conceito de máximo é apropriado para processos biotécnicos, apesar de possuir também um significado geral. A biotecnologia tem, é claro, conceitos especificos. O conceito de controlo dinâmico de processo é um exemplo:

"A dosagem de substrato adaptada ao estado celular, quando aplicada a uma cultura de microorganismos em crescimento sincronizada, resulta em coeficientes de consumo mínimos".

Este conceito só tem utilidade na aplicação à biotecnologia.

Outros exemplos de conceitos em biotecnologia incluem a fermentação de alta-velocidade, fermentação em substrato sólido, fermentação em solventes não-aquosos, fermentação em substratos mistos/culturas mistas, combinação de multiplicação celular e formação de produtos, bem como combinaçôes de tratamento de afluentes e formação de produtos. Uma característica comum a todos estes exemplos é que a sua realização técnica baseia-se sempre no mesmo princípio, embora os detalhes possam variar infinitamente.

Os exemplos referidos mostram como as exigências económicas dos processos industriais podem estar ligadas às propriedades específicas dos sistemas biológicos, o que cria os fundamentos teóricos para a exploração total das capacidades dos sitemas biologicos.

\section{Questões particulares a serem abordadas pela biotecnologia}

Os parágrafos seguintes introduzem alguns dos problemas envolvidos na investigação tecnológica, que terão de ser examinados para que uma ciência da tecnologia possa ser desenvolvida de um modo prático e sistemático.

1. A passagem do conhecimento científico para a produção é um processo descontínuo. A organização da investigação tecnológica terá então de ser pautada pelo desenvolvimento económico.

2. Ao definir as tendências da investigação tecnológica, as questð̃es necessárias terão de preceder as desejáveis. Seguir este princípio não significa limitar os poderes criativos para resolver estas tarefas, mas antes orientá-los para a solução óptima, em termos de qualidade e de tempo.

3. A distinção entre os desvios aos estados da produção, durante o processo de produção, susceptíveis de influenciar os resultados e os que o não são, torna-se um meio fundamental para acelerar a introdução de novos processos.

Estas questōes assumem particular importância para a introdução da produção biotécnologica porque:

- a base industrial da biotecnologia é ainda pequena; - a proximidade entre a investigação na biotecnologia e os padrōes científicos avançados torna a produção biotecnologica atractiva;

- a grande complexidade dos processos biológicos complica a ponderação de todos os factores em jogo. Estes problemas mostram que os componentes da construção da tecnologia com uma ciência estão disponíveis. Se encarados, resolvidos e usados na conjectura certa, poderão certamente contribuir para um melhor controlo e obtenção de fundamentos mais sblidos de produção. 


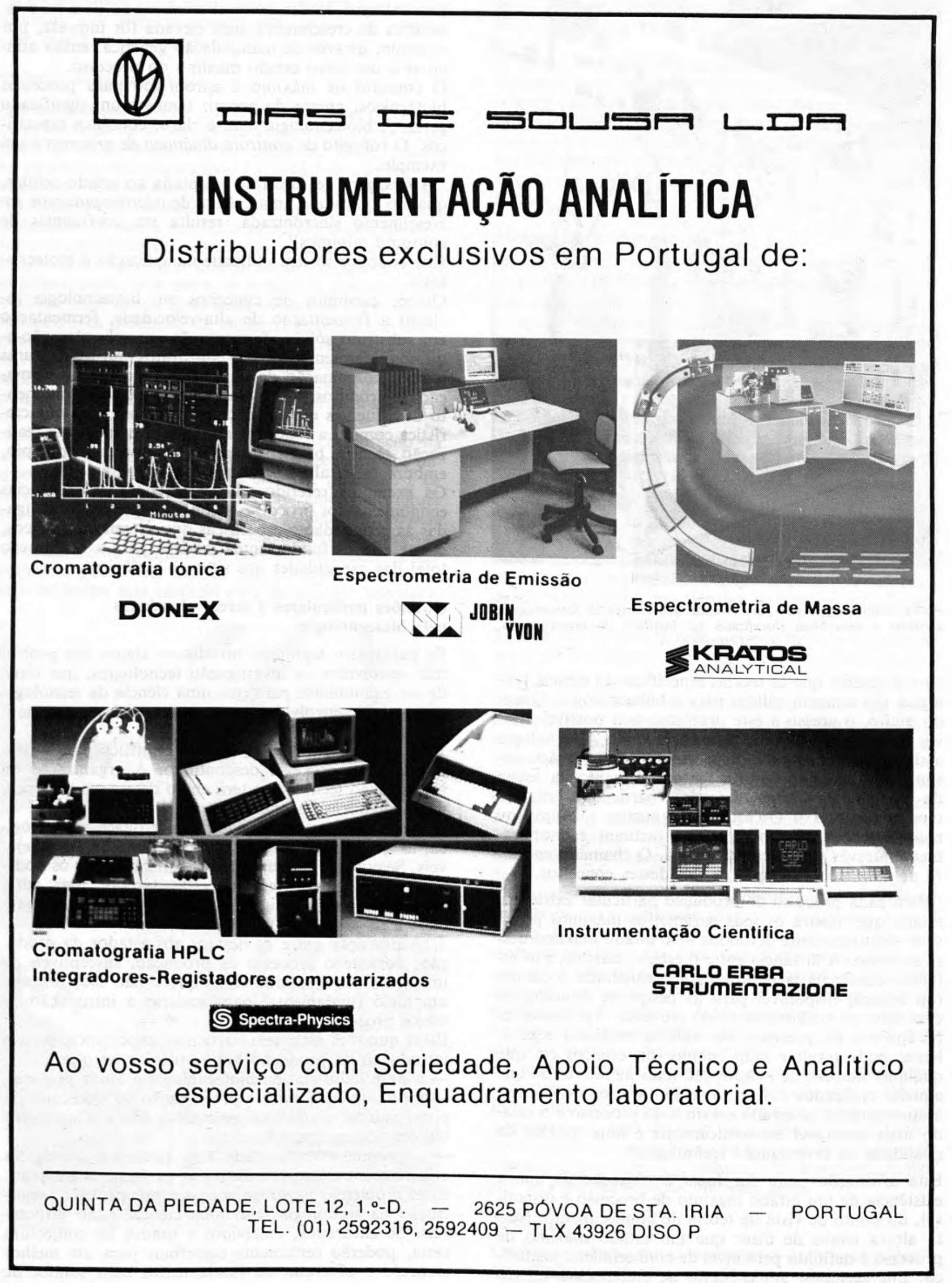




\section{O Citocromo P450 na metabolização de drogas}

\section{Introdução}

Diariamente o nosso organismo absorve diversos tipos de compostos, na sua maioria orgânicos, que por não fazerem parte dos seus constituintes normais são conhecidos como xenobióticos (do grego xeno = estranho e biótico = vida).

Entre estas substâncias, que podem de algum modo afectar o equilíbrio celular, incluem-se os medicamentos, alguns dos quais são administrados quase continuamente em situaçð̄es graves, os aditivos alimentares e os poluentes como por exemplo o fumo do tabaco. A biotransformação dos xenobióticos, conjunto de reacçōes metabólicas que os convertem em compostos geralmente mais polares, é o processo que permite ao organismo eliminar mais ou menos rapidamente aqueles compostos orgânicos, evitando a sua acumulação. As reacçōes de biotransformação de xenobióticos consideram-se de dois tipos:

- fase I, que inclui oxidação, redução e hidrólise, todas elas introduzindo um grupo funcional susceptível para a fase II

- fase II, que engloba as reacções que originam compostos rapidamente excretáveis devido à sua elevada polaridade, tais como glucuronidos, derivados de aminoácidos, de ácidos mercaptúricos, ou ainda conjugados na forma de acetato ou sulfato.

\section{ESOUEMA 1}

\section{Glucoronido conjugado do acetaminofeno}

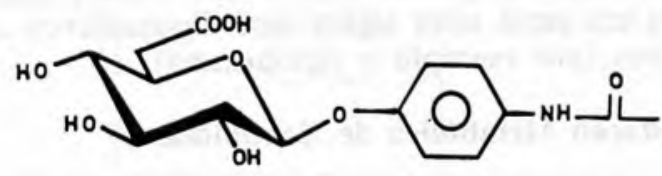

Conjugado do ácido fenilacético<smiles>[R][C@H](NC(=O)Cc1ccccc1)C(=O)O</smiles>

De facto apenas dois tipos de compostos escapam a este destino - são eles os anestésicos porque sendo apolares penetram em todas as membranas e os muito polares precisamente porque estes últimos não podem penetrar nas células.
O conhecimento das reacçð̃es da fase I e II é de importância fundamental para a compreensão da actividade farmacológica e toxicologica dos xenobióticos. Porém, nem sempre a metabolização conduz à destoxificação. Com efeito, se em muitos casos o meiabolismo leva directamente a produtos polares rapidamente excretáveis, há no entanto outros exemplos em que os xenobibticos são convertidos em metabólitos que contribuem ou são responsáveis por efeitos biologicos atribuídos ao agente administrado. Citamos como exemplos os fármacos inactivos cujo metabolito é o verdadeiro agente farmacológico e o de espécies que são capazes de se combinar quimicamente com o ADN, ARN e proteínas celulares e assim contribuir ou mesmo provocar a transformação de células normais em tumorais.

A oxidação metabólica dos xenobióticos é o principal processo de biotransformação destes. Uma metaloproteína, o citocromo $\mathrm{P} 450$, é a peça fundamental destas reaç̧ð̄es.

Esta enzima é a responsável pela maioria das reacçð̄es de oxidação de diversos substratos, através duma série de reacçð̄es redox.

Abordaremos de seguida o papel do sistema citocromo $\mathrm{P} 450$, os tipos de reacçōes e substratos, bem como os factores que influenciam o seu funcionamento alterando assim de algum modo a biotransformação dos xenobióticos.

\section{O Citocromo P450}

\subsection{Estrutura e função}

O citocromo P450 é uma enzima ubiquitária constituída por duas subunidades polipeptídicas e por um grupo prostético ferro-porfirina (1). Encontra-se principal-

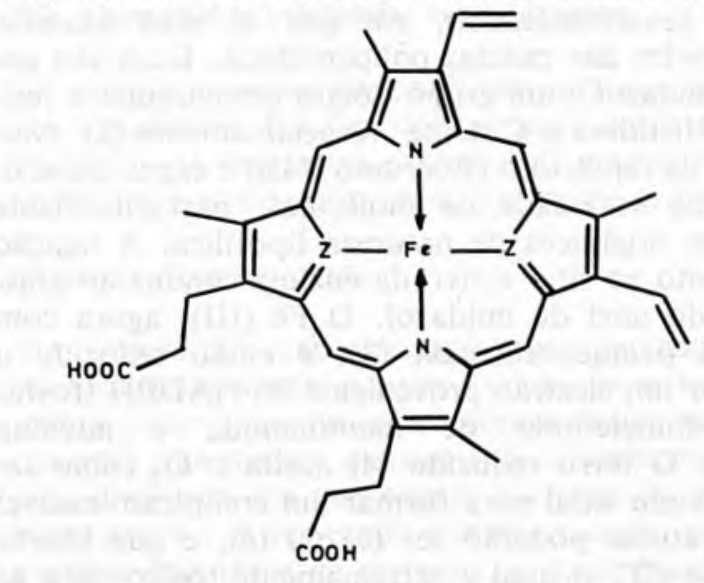

(1)

\footnotetext{
a Faculdade de Ciências de Lisboa.
}

b Faculdade de Farmácia de Lisboa. 
mente no fígado, verdadeiro centro de destoxificação do organismo, e ainda nas cápsulas supra-renais e nos pulmões. Ao contrário da maioria dos citocromos, que se localizam nas mitocôndrias, o citocromo P450 no figado situa-se no retículo endoplasmático liso, estrutura membranosa que se distribui pelo citoplasma das células, o que o torna mais acessivel aos xenobióticos.

$\mathrm{Na}$ reacção catalizada pelo citocromo P450 é consumida uma mole de oxigénio molecular e introduzido um átomo de oxigénio no substrato, permitindo incluir aquela enzima no grupo dos mono-oxigenases (esquema 2). O mecanismo da reacção envolve um ciclo cata-

ESOUEMA 2

$$
\mathrm{RH}+\mathrm{O}_{2}+\mathrm{NADPH}+\mathrm{H}^{+} \longrightarrow \mathrm{ROH}+\mathrm{H}_{2} \mathrm{O}+\mathrm{NADP}^{+}
$$

lítico no qual o ferro do grupo prostético varia de número de oxidação e pode-se considerar dividido em duas etapas: (1) activação do oxigénio para formar um intermediário oxidante e (2) transferência do oxigénio para o substrato (esquema 3 ). No entanto o ciclo catalítico não está ainda completamente elucidado especialmente no que diz respeito à estrutura correcta da espécie oxidante e ao mecanismo de transferência do oxigénio.

ESQUema 3

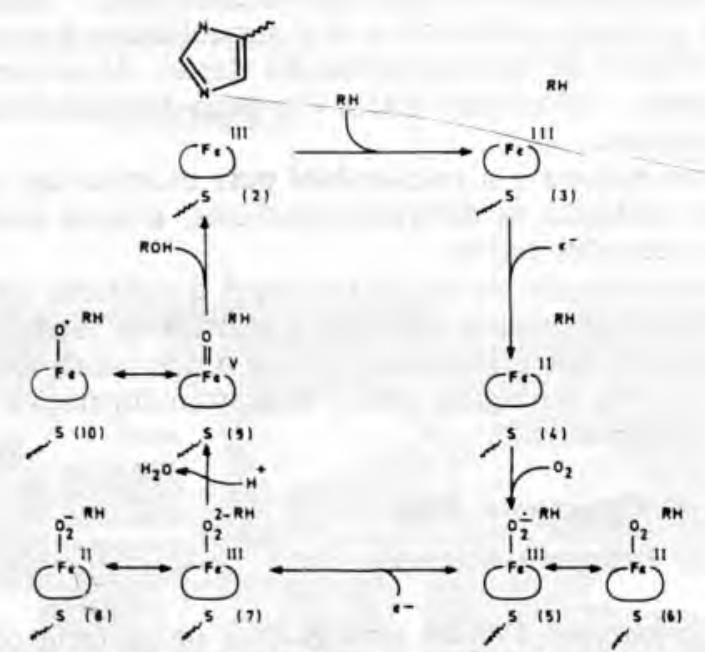

Activação do oxigénio. O citocromo P450 quando não está ligado ao substrato contém o ferro na forma $\mathrm{Fe}$ (III) hexacoordenado, em que os dois ligandos axiais provêm das cadeias polipeptídicas. Estes são um anel de imidazol e um grupo tiolato pertencentes a resíduos de Histidina e Cisteina, respectivamente (2). Neste estado de repouso o citocromo P450 é capaz de se ligar a uma variedade de moléculas, particularmente compostos orgânicos de natureza lipofílica. A ligação do substrato ao sítio activo da enzima conduz ao afastamento do anel de imidazol. O Fe (III), agora com geometria pentacoordenada (3), é então reduzido a $\mathrm{Fe}$ (II) por um electrão proveniente do NADPH-(fosfato do dinucleótido de nicotinamida e adenina reduzido). $\mathrm{O}$ ferro reduzido (4) aceita $\mathrm{O} \mathrm{O}_{2}$ como segundo ligando axial para formar um complexo instável cujas estruturas poderão ser (5) ou (6), e que liberta superoxido $\left(\mathrm{O}_{2}^{-}\right.$, o qual é extremamente toxico para as células) se não for subsequentemente reduzido. A redução ocorre com transferência doutro electrão proveniente do NADPH, tendo como produto um interme- diário, (7) ou (8), que é o percursor directo do reagente oxidante. Este último possui um número de oxidação pouco usual para ferro, muito provavelmente $\mathrm{Fe}(\mathrm{V})$ (9), embora não seja de excluir a estrutura (10) que contém $\mathrm{Fe}(\mathrm{IV})$. Em qualquer dos casos será este agente oxidante poderoso que adiciona o átomo de oxigénio ao substrato.

Transferência do oxigénio. O mecanismo que permite ao complexo $\mathrm{Fe}^{\mathrm{v}}=0$ transferir o oxigénio para o substrato pode variar consoante a função química deste. A oxidação de cadeias saturadas é a reacção que está mais bem estudada. Possivelmente aquele reagente oxidante abstrai um átomo de hidrogénio à cadeia alquílica formando-se um radical livre e $\mathrm{Fe}^{\mathrm{IV}}-\mathrm{OH}$ os quais reagem para produzir o metabolito hidroxilado (esquema 4). Uma vez oxidado, o substrato dissocia-se do citocromo P450 e este volta ao seu estado de repouso.

$$
\begin{aligned}
& \text { ESQUEMA } 4 \\
& \qquad \mathrm{Fe}^{\vee}=\mathrm{O} \stackrel{\mathrm{HCR}_{3}}{\longrightarrow} \mathrm{Fe}_{\mathrm{e}}^{\mathrm{IV}}-\mathrm{OH} \cdot{ }^{\circ} \mathrm{CR}_{3} \longrightarrow \mathrm{Fe}^{\mathrm{II}} \cdot \mathrm{HOCR}_{3}
\end{aligned}
$$

\subsection{Substratos}

A gama de substratos capaz de serem oxidados é enormíssima (basta lembrar que quase todos os fármacos sofrem oxidação metabólica) pelo que não será de estranhar que não exista só um citocromo P450 mas sim uma família de enzimas, cada uma com especialidade para um grupo de substratos. No entanto todas elas são selectivas para compostos lipossolúveis, o que deriva da sua interacção com a membrana lipídica do retículo endoplasmático.

O espectro electrónico do citocromo P450 oxidado possui um máximo de absorção a $420 \mathrm{~nm}$ no seu estado de repouso. Porém este máximo é deslocado quando os substratos se ligam à enzima, podendo classificar-se aqueles consoante a zona do espectro onde aparece a nova banda. Temos assim os substratos tipo I, que provocam um desvio para $385 \mathrm{~nm}$, enquanto os substratos tipo II desviam o máximo para $430 \mathrm{~nm}$. Os espectros tipo II são característicos de compostos que contêm azoto e outros heteroátomos com orbitais não ligantes como a anilina, esteróides e alcoois. As características dos compostos tipo I são menos definidas, embora em geral estes sejam mais lipossolúveis que os anteriores (por exemplo o ciclohexano).

\section{Oxidação Metabólica de Xenobióticos}

$\mathrm{Na}$ sua maioria os compostos susceptíveis de serem oxidados pelo citocromo P450 são aromáticos e/ou contém heteroátomos. Por isso a oxidação destas funçð̃es químicas são as reacçōes mais importantes na metabolização dos xenobióticos.

\subsection{Compostos aromáticos}

A oxidação metabólica destes compostos consiste na hidroxilação do anel aromático e pode ser representada pelo esquema 1 em que $\mathrm{R}$ corresponde àquela função. Os dados existentes sugerem que o metabolito resultante da mono-oxigenação directa do núcleo aromático pelo citocromo P450 é um epóxido ou óxido de areno (12), o qual sofre um rearranjo para gerar o respectivo 